\title{
DENYS WYATT HARDING ON ENTERTAINMENT AND ON READING
}

\section{Meta Grosman}

Entertainment and the process of reading are two spheres of human activity which have kept Professor Harding's interest for more than forty years. Time and again he would focus his attention on them: studying the nature of these activities, their relation to other human activities, their impact upon the individual and their role in society as a whole, and examining individual features of the reading process, analysing various misconceived notions about the nature and position of these activities in human life and investigating the possibilities of improving the capacity to respond to art at a more practiced level. In this way - approaching the problems of entertainment and reader response from different points of view and elaborating various details and aspects over several decades - his sustained efforts to penetrate into these activities have resulted in an important body of knowledge encompassing a far-reaching concept of entertainment and of reading built upon a well-balanced account of them as integral human activities, and of their wider social relevance.

Sometimes succinctly characterized as cultural pursuits, these two activities certainly fall into the category of the most complex forms of human behaviour in civilized societies, and are, accordingly, notoriously hard to study systematically or to examine experimentally. Because of this they have been subject to rather vague assumptions and predominantly metaphorical descriptions. Up till now studies in this field seem to have passed quite untouched by the fast development characteristic of so much psychological thought and experimentation in some other spheres of human behaviour. Thus Professor Harding's work has kept its original challenge of a profound and honest examination of a scarcely known and hard-tounderstand area of important human activities, still of topical interest today.

The purpose of this study is to present Harding's writings in the related fields of entertainment and the process of reading, especially the following of his studies whose interest centres on the two subjects which are, naturally, referred to and discussed also in some of his other works:

"Adult Education and Adult Entertainment" (1934),

"The Place of Entertainment in Social Life» (1934),

"How Do You Enjoy Yourself?« (1934),

"Some Views of Yours on Entertainment« (1937),

»The Role of the Onlooker« (1937),

"The Social Background of Taste in Music" (1938), 
»The Social Background of Taste in Music II - Individual Growth in Taste« (1938),

"Skills of Enjoyment« (1948),

»Psychological Processes in the Reading of Fiction« (1962),

»Reader and Author« (1963),

"The Notion of 'Escape' in Fiction and Entertainment« (1967),

„Considered Experience: The Invitation of the Novel« (1967),

»Practice at Liking: A Study in Experimental Aesthetics« (1968),

»The Bond with the Author" (1971).

As it is obvious from the dates of publications, Professor Harding had treated the wider topic of entertainment before he turned to examine the narrower problem of the reading process; it had kept his attention - as a major preoccupation - for a shorter time than the process of reading. Apart from observing the chronological order of appearance, I will attempt no differentiation between the two topics in this presentation. The reason for this decision lies in the fact that the treatment of these two activities is frequently intertwined in his studies, so that his studies of entertainment include all forms of the so-called display entertainment, film, drama, fiction, and his later studies of the reading process always cover the reading of both what would be categorized as serious literature and as subliterature, and regarded as entertainment. Thus most of his studies refer to both of these activities. Keeping in mind the problems of both activities, he seems to shift the central interest of his studies from the broader subject of entertainment to the narrower problems of the reading process, and to further details of the same. Along with this development we can follow a simultaneous everpresent interest in the possibilities of improving the capacity to respond to art, which eventually crystallizes to become the central preoccupation of some of his studies.

\section{ENTERTAINMENT}

"Adult Education and Adult Entertainment« (1934) $)^{1}$ is Professor Harding's first attempt to outline some integral features of entertainment and to call attention to its important place in the economy of human interests. Currently accepted views disapproving of entertainment and simply suggesting that it should be replaced by something else are neither responsible nor offer any sound basis for the improvement of entertainment. To develop entertainment as good as it might be, its new potential social function and value should be carefully examined. Professor Harding's study tries to furnish the first step towards this aim. To reveal its basic functions he first tries to analyse »the social situation « set up by entertainment:

In films, plays, novels, jokes, popular songs and pictures, and in a large part of the newspapers it is clear that the entertainer is describing or presenting what he takes to be interesting situations in what he takes to be an appropriate light. He expects his audience to agree that the situation is interesting and the attitude taken up towards

1 »Adult Education and Adult Entertainment«. Adult Education, Vol. 7, Part 1 (September 1934): 18-24. 
it appropriate; - implicitly he is asking for their sanction for his interests and evaluations. ... There occurs between the public and its entertainers a reciprocal sanctioning and reinforcement of each other's interests, ideals, desires and attitudes; the sanctioning, broadly, of the community's emotional life, and thus, indirectly, of its conduct and morality. Let me make the people's films and I care not who makes their laws. ${ }^{2}$

The prominence of social communication and sanctioning in mass circumstances accounts for the powerful influence of much entertainment upon the public. Its effects, i. e. its setting "the tone of popular emotional response and therefore the subtler points of everyday conduct" is even stronger because the human capacity for feeling and evaluation is largely neglected in a system of education primarily concerned with the acquisition or improvement of skills, increase of knowledge, and improved capacity for thinking, thus leaving a gap which is readily filled by popular entertainment. Its penetrating influence can be understood by analogy with our daily experience with our friends and fellow-men, which in the form of daily gossip and conversation comes to form our emotional attitudes and our expectations in much the same way as entertainment. A friend telling us what he saw last night is doing essentially what novelists, playwrights, journalists, comic songsters, and film industries are doing: "He is presenting, more vividly or less, some of what he considers the more interesting possibilities of living, presenting them in what he regards an appropriate light, and expecting you to sanction these interests and attitudes by forming a responsive and sympathetic audience. $\ll^{3}$

Entertainment is thus seen basically as a heightened form of such emotional exercise and seducation « and as continuous with other social experience and not as separate or different from it. Because of its important influence it should be carefully studied together with the possibilities of its improvement.

Professor Harding's next study, »The Place of Entertainment in Social Life« (1934), ${ }^{4}$ is his most complex statement of the problems concerning entertainment, some of which will be examined in more detail in his later writings. The explicit purpose of his preliminary discussion is to try to clarify some uncertain notions about psychological mechanisms involved in entertainment. His analysis first centres on the inadequacy of the contemporaneous notion that spectators of entertainment are passive and experience vicarious satisfaction suggested by daydreams and fantasy wishfulfilment based on identification with performers. Such a theory of vicarious satisfaction assuming "that there occurs in the spectator an unconscious identification of himself with the performer, so that the impulses he supposes the performer to be satisfying are also satisfied in him «, ${ }^{5}$ Harding says, "must mean that the spectator is in an abnormal social relationship with the performer and fails to treat him as someone other than himself . Though it is hard to prove or disprove such an identification, the claim that it always occurs, together with vicarious satisfaction, or that

2 Ibid., p. 20.

Ibid., p. 23.

4 "The Place of Entertainment in Social Life." The Sociological Review, Vol. 26, No. 4 (October 1934): 393-406.

5 Ibid., p. 395. 
it constitutes the normal mechanism of entertainment, is certainly exaggerated. Taken literally, it could lead to the conclusion that any admiration of, or respectful attention to, other people comes about because we are identified with them or gain vicarious satisfaction from their activities. A more tenable solution is suggested: we enjoy seeing other people do things that we would enjoy doing ourselves simply because $" w e$ possess an ill-defined sentiment of liking for other human beings as such ${ }^{6}{ }^{6}$ Our social relationship with an entertainer can accordingly be viewed as not essentially different from our relations with other people in many ordinary life situations. though the activity we watch in entertainment is of a more exciting kind and the position we occupy in watching is peculiar:

The peculiarity of the entertainment situation and of those like it is that we remain in the position of spectators without becoming "practically" involved. Such situations, however, in spite of our seeming passivity, are not without importance, since the interest we feel and the attitude we take up are inevitably contributing in some degree to the organization of our emotional life. To wipe out, supposing it possible, the effects of all the occasions on which a man was merely a spectator would be profoundly to alter his whole character and cultural status.'

The related ideas of vicarious satisfaction, identification, and wish-fulfilment are most frequently applied to novels, plays and films, which represent entertainment of greater practical importance. They are in particular applied to what is regarded as inferior entertainment and not to serious literature, though such differentiation certainly seems untenable from the reader's point of view, since serious literature also provides the reader with characters whom he may sympathize with. If entertainment is regarded as being sessentially a matter of sociable communication, and continuous in function and process not with daydreaming but with gossip ${ }^{8}$ it is possible to see how the represented situation is "lived through" without the occurrence of identification and vicarious experience:

"Although we are not identified with any one of the characters in a play or novel we are nevertheless held in an imagined social relationship with them all, as if we were invisible and impotent spectators among them. In this way we may experience intense feeling ...." ${ }^{9}$

If the view that gossip and representational entertainment fulfil the same function is tentatively accepted, preliminary speculations about such functions become possible. Besides relieving us of the muddle of "real life« and the fluctuations and inhibitions produced by actual events,

it seems that both gossip and entertainment have the function of reminding us of the more interesting possibilities of living, and of convincing us that important things do happen to the sort of people in whom we have a social interest. ... they represent events in such

${ }^{6}$ Ibid., p. 396.

7 Ibid., p. 397.

${ }^{3}$ Ibid., p. 399.

' Ibid., p. 399. 
a way that we remain in the position of a spectator, not involved except so far as our interest in human activity as such involves us. In spite of our emotional response we cannot be called upon to take part.

The unreality of the situations shown in entertainment presents no problem to the spectator who knows that the events of a film or novel are unreal in the sense that they never happened. In spite of this they can "draw attention to certain real possibilities of human life and feeling « and because of this "the unreality of situations represented is likely to be of small importance compared with the reality of the communication they make possible ".11 The spectator's and reader's primary concern lies with the interesting human possibilities which the fiction allows the entertainer to bring up and comment on. And accordingly they respond to what they recognize "more or less consciously to be a social presentation of events and not to events themselves «.12 Only a very naive audience or small children fail to recognize this fact.

The tendency to view entertainment as sescape occurring by means of the fantasy process fails to recognize that the process of being entertained is not itself the same as daydreaming. The possibility that it may stimulate the latter does not change this basic fact and Professor Harding emphasizes that entertainment is an escape only in the way in which any interesting activity may be an escape from some other activity; similarly, one "forgets oneself only in the way one does this in any interesting pursuit. So Professor Harding concludes that sentertainment as such is a normal human activity which, like gossip or music or politics, may be given varying prominence, and may attain different degrees of excellence, in different cultures «. ${ }^{13}$ However, a more precise analysis of the complex interests, sentiments and attitudes that it reflects will only be possible when actual entertainment has been examined in more detail.

To gather facts which would facilitate a serious investigation of entertainment and its functions, Professor Harding addressed sixteen questions to the readers of The Highway in his article "How Do You Enjoy Yourself « (1934). ${ }^{14}$ The questions are geared primarily towards revealing the various attitudes to entertainment, the ways in which entertainment is obtained, the value placed on it, the functions attributed to it, or rather the effects as experienced by its consumers. That is why the readers of The Highway are explicitly asked »to give the information spontaneously«, to say »what the facts are , rather than what they feel they ought to be. Opinion could be added too, but the facts and opinion should be kept separate.

Professor Harding's analysis of the answers sent by over two hundred people appeared as "Some Views of Yours on Entertainment" in the April 1937 issue of The Highway. ${ }^{15}$ It covers only a small part of the materials gathered, above all wthe question of what kind of value people place on

${ }^{10}$ Ibid., pp. 400-1.

"Ibid., p. 401.

12 Ibid., p. 402.

${ }^{13}$ Ibid., p. 404. $38-39$.

${ }^{14}$ "How Do You Enjoy Yourself?« The Highway, Vol. 27 (November 1934):

15 "Some Views Of Yours on Entertainment." The Highway, Vol. 29 (April 1937): $180-82$. 
entertainment - whether, for instance, it is a positive good, or a consolation to be tolerated, or an injurious drug " ${ }^{16}$ A large portion of respondents held what can be called the medicine view, that is, they were inclined to regard entertainment as justified not by the direct satisfaction it gives, but by the contribution it makes to some other aspect of their lives ${ }^{17}$ irrespective of whether they would describe it as a consolation for the less pleasant parts of life or speak about its quality and quantity in terms of its compensatory, medicinal, or doping function. Such answers, Professor Harding explains, tend to overlook the direct pleasure derived from entertainment, without which it could hardly have the desired effects:

»In judging the significance of this kind of attitude torvards entertainment we have to bear in mind that the medicinal function can never be the whole story: entertainment could never be a successíul tonic or anodyne unless it were a direct pleasure in itself. None of my correspondents... suggests that entertainment is a bitter medicine. ... there must be many who value it far more for its direct pleasure than they want to realize. ${ }^{1 s}$

Also some other answers, for instance that it is better to have small doses of entertainment than big ones, obviously reflect the commonly accepted view that entertainment is less worthy than work or education or enjoyment of the arts. Along with uncertain notions, popular opinion about entertainment thus seems to share also a rather puritanical attitude to such activities, as is characteristic also of the more critical discussions of them.

\section{FROM ENTERTAINMENT TO THE PROCESS OF READING}

»The Role of the Onlooker", 19 published in the same year as "Some Views of Yours on Entertainment", moves in its central interest from entertainment in general to the representational entertainment of film, drama, and in particular of fiction. This shift, anticipated with the emphasis laid upon the importance of representational entertainment already in The Place of Entertainment in Social Life«, may be said to represent a further development from a general to a more specialized interest in Harding's writings. Such explanation seems probable since we can trace a similar tendency to turn to the discussion of more specialized problems also in Professor Harding's contemporaneous studies of the possibilities of acquiring and improving the skills of enjoyment in arts. The wider topic of entertainment, especially of its important formative influence upon man, of course, is never lost sight of in his later writings, which proceed from unchanged premises.

Written for the different readership of Scrutiny "The Role of the Onlooker" sets out to describe in detail the activity of the spectator and

${ }^{16}$ Ibid., p. 180. The other topic discussed is the place of sex in entertainment. Some of the gathered materials were used for his later "The Notion of 'Escape' in Fiction and Entertainment«. Cf. note 45 for bibliographic details.

${ }_{17}$ Ibid., p. 180.

18 Ibid., p. 180.

19 "The Role of the Onlooker.« Scrutiny, VI (1937): 247-58. 
reader. ${ }^{20}$ It is an attempt to answer the questions which the novel reader or playgoer swho knows well enough that he at least is not indulging in escape, that he is not passive, that he enjoys no vicarious satisfaction ${ }^{21}$ may find himself wondering about when he wants to know what he is doing in reading, what is the nature of his activity and of the imaginative response he is making.

To discuss sthe part played by the spectator or reader, what is the nature of his response? What mode of activity is he engaged in? Or, to put it differently, with what other modes of activity do we tacitly contrast his Response?" Professor Harding first outlines four modes of activity. These four modes - the operational relationship to objects and events in which things are actually done, the intellectual comprehension of things and events around us, simple enjoyment of experience at perceptual level, and the response of detached evaluation - can be differentiated even though they only seldom appear in isolation. Professor Harding points out that once the value judgement is made, that is, once the spectator assesses the event in the light of his interests, desires, sentiments and ideals and feels it to be noteworthy, commonplace, agreeable or disagreeable, tragic, funny, contemptible or heroic, his relationship to the event has gonc beyond mere comprehension.

He next examines the role of the onlooker watching actual events of interest to him because they disclose or make more vivid to him scertain of the possibilities of his surroundings«. The daily activity of looking at various events affects the onlooker and his expectations, hopes and anxieties in proportion to two factors: the sentiment that binds him to the participant and the importance that he attributes to the event in the light of his own values. Such a detached looking at events which includes an evaluation exercises a great formative influence on the onlooker. Watched without personal involvement the events are viewed in a more distant perspective and related to a more extensive system of information, beliefs and values. Because of this the detached evaluative response tends to be more widely comprehensive and comes to have

the utmost importance in building up, confirming and modifying all but the very simplest of our values. It is as onlookers from a distance that we can most readily endure the penetration of general principles among our sentiments. ${ }^{22}$

In this way the events we view from a distance, without any direct operative response, come to have a profound influence upon us:

${ }^{20}$ The importance of a detailed and precise description of an activity before we can begin to understand it is described in his study "Varicties of Work and Leisure," Journal of Occupational Psychology, No. 12 (Spring 1938), p. 114: "To understand a piece of activity (necessarily in reference to a particular individual) we need to discuss the direct satisfaction it offers; its indirect incentives and their vividness; its psychological cost; the degree of concentration it demands (its exigence); its 'difficulty' (the degree to which it lies within or beyond the individual's present skills or insight); and, finally, whether it is agreeable or disagreeable.«

"2 "The Role of the Onlooker", p. 247.

22 Ibid., p. 252. 
The event we look on at from a distance affects us, but it is set in a wider context than the urgencies of participating relationships usually permit us to call up around events. And for this reason, if we could obliterate the effects on a man of all the occasions when he was 'merely a spectator' it would be profoundly to alter his character and outlook..$^{23}$

Thus the viewer's future expectations are formed and so are his beliefs of what is "the kind of thing that does happen " and what is natural and what is not established. This process of cultural moulding is in effect while everything we look at is also treated as an object lesson by our fellow spectators sanctioning or withdrawing the sanction of our feelings about the events.

In this respect the experience represented symbolically, in language, opens up even more interesting possibilities than the direct experience of our surroundings. We can represent to ourselves actual experiences of our past, or transfer to ourselves things that have happened to others, and imagine also physically impossible happenings. When the possibilities of experience are no longer represented privately but communicated we pass to cooperative make-believe play of children and to gossip. In gossip various possibilities of experience are communicated and evaluated. The roles of "entertainer and audience are differentiated and can also be passed backwards and forwards from one person to another, while the audience's attitude of agreement or disagreement may be expressed directly to the speaker. The most important feature of gossip is the implied attitude of the speaker coming to expression in his control of the directedness of his statement.

But the essential fact in gossip as in entertainment is that the speaker who raises a topic is presenting what he takes to be an interesting situation - actual or possible - in what he regards as an appropriate light. He expects his hearers to agree on the interest of the situation and the fittingness of his attitude' whether it be the hushed fascination with which he talks of cancer or his truculent satisfaction at the nation's increased armament. ${ }^{24}$

From this description of gossip Professor Harding takes only one step to come to the representational art of the writer and film producer:

The playwright, the novelist, the song-writer and the film-producing team are all doing the same thing as the gossip, however innocent they may be of witting propagandist intentions. Each invites his audience to agree that the experience he portrays is possible and interesting, and that his attitude to it, implicit in his portrayal, is fitting. In the less developed leveis of entertainment the process is chiefly one of reinforcing commonplace values in a trivially varied array of situations. In the representational arts, most obviously in literature, the author invites his audience to share in exploration, an extension and refinement, of his and their common interests; and, as a corollary, to refine or modify their value judgments. ${ }^{25}$

On the basis of his considerations Professor Harding makes it obvious that attempts at over-simple statements of the difference between "art « and sentertainment« should be discouraged, since neither of them forms a homo-

23 Ibid., p. 253.

24 Ibid., p. 257.

${ }^{25}$ Ibid., p. 258. 
geneous category of quite the kind it is sometimes supposed to. Such challenging questions as whether cur taste in gossip is the same kind of thing or not as our taste in films and trivial fiction, and whether the latter is continuous or not with our taste in literature, demand further examination. So do the notions of passivity and activity of vicarious satisfaction and of escape.

It is these last-mentioned concepts that are in the focus of »Psychological Processes in the Reading of Fiction « ${ }^{26}$ (1962). Thus Professor Harding turns to further examination of the reading process only twenty-five years after the publication of »The Role of the Onlooker", a time marked by the publication of his two books on social psychology and numerous studies in diverse fields. ${ }^{27}$ Though the basic premises remain unchanged, the presentation of and the emphasis on individual elements are different, and his detailed examination of the psychological concepts usually used in the discussion of the reading process - passivity, identification and vicarious satisfaction - offers challenging conclusions revealing their fundamental inadequacy.

Agreeing vith those who maintain "that the numerous and extremely dissimilar activities conventionally grouped together as the arts don't form a separate psychological category«, Professor Harding decides not to discuss fiction within the framework of general aesthetics. He decides on such an approach not only because he is of the opinion that very few literal statements applying to a novel, a landscape painting, a porcelain dish and a piece of music are at all illuminating about any one of those things, but because he is persuaded that the very nature of fiction merits and justifies a different examination:

\begin{abstract}
A novel is so distantly related to many other sorts of art, and so closely related to activities that are not included among the arts, that an approach through aesthetic generalizations would be restricting and misleading. It may seem, perhaps, that the form of a novel and the style of a novelist can be discussed in terms equally applicable to other arts, but I suspect that it can be done only by substituting metaphor and analogy for literal statement..$^{28}$
\end{abstract}

Persuaded that "more important aspects of fiction are illuminated if the reader of a novel is compared with the man who hears about other people and their doings in the course of ordinary gossip ", Professor Harding proposes to view sthe reading of a novel as a process of looking on at a representation of imagined events, or rather, of listening to a description of them. ${ }^{2 s}$ His outline of the necessary premises taken from his previous work redefines the importance of the time spent in looking on at events in a non-participant evaluative relation. Stronger emphasis is laid on the elements of fantasy; however, its relatedness to the real needs is always kept in mind, since forms of fantasy "give expression to perfectly real preoccupations, fears and desires, however impossible the imagined events embodying them «.$^{30}$ Especially the possibility of things that might happen, encountered at its simplest

${ }^{26}$ "Psychological Processes in the Reading of Fiction." British Journal of Aesthetics, Vol. 2 (April 1962): 133-47.

${ }^{27}$ For details consult "Bibliography of D. W. Harding's Works« in Acta Neophilologica, XV (1982), pp. 86-90.

${ }_{28}$ "Psychological Processes in the Reading of Fiction", pp. 133-4.

${ }^{29}$ Ibid., p. 134.

30 Ibid., p. 136. 
in the child's "Suppose..." technique, brings about "a vast extension of the range of possible human experience that can be offered socially for contemplation and assessment «..$^{31}$ Like a great deal of gossip and everyday narrative, fiction and drama - irrespective of whether they are true or fictional - basically »invite us to be onlookers joining in the evaluation of some possibility of experience ${ }^{32}$ The use of fantasy only makes it more evident that fiction is a convention of communication: an accepted technique for discussing the chances of life, a convention for enlarging the scope of the discussion we have with each other about what may befall. As a consequence of this, full grasp of fiction as fiction is a sophisticated achievement, only gradually attained by children and sometimes not fully mastered by the less sophisticated adult. Though not in the position to answer back, the reader is still active in such a discussion by accepting or rejecting what the author assesses in terms of possible events and suggests as an appropriate attitude. Though the reader may not consciously formulate his agreement or disagreement, his discriminations come to expression in his enthusiasm for an author's work or disappointment with it.

In the second part of his study Professor Harding proceeds to describe in detail the reader's active part in his reception of fiction, and to show why the concepts of identification and vicarious satisfaction, implying the reader's passivity, are inadequate.

Here again the emphasis is laid on the process of imagining which forms the basic connection between the onlooker and the reader and a real or an unreal event:

The fundamental fact is that we can imagine ourselves in a situation very different from the one we are in, we can create images of the sensations we should have, we can become aware, in part, of the meanings we should see in it, what our intentions, attitucles and emotions would be, what satisfactions and frustrations we should experience. ${ }^{33}$

The same basic process of imagining is at work when, looking out of the window, you imagine yourself out in the rain with every possible sensation of such a situation, when you see a man walking in the rain and, assuming a fundamental likeness between yourself and him, have an imaginative or emphatic insight into his experience, or when you watch a film of a man in such a situation, or read of him in a novel.

The reader's imaginative insight into characters may take different forms and be accompanied by various attitudes:

The reader may see resemblances between himself and a fictional persona only to regret them (and perhaps hope to become different); is this recognition of resemblance 'identification'? He may long enviously to be like a fictional character so different from himself that he discounts all possibility of approximating to him; is this admiration 'identification'? He may adopt the character as a model for imitation, more or less close and successful, and it may be this process to which 'identification' refers. Or he may be given up, for the duration or the novel or film, to absorbed empathy with one of the characters....

31 Ibid., p. 138.

Ibid., p. 138.

Ibid., p. 140. 
The onlooker's observation of other people or of personae in fiction and drama may be accompanied by a preference for some, by specially sensitive or full insight into some, by awareness of likenesses between himself and some (not necessarily those he admires), and by a wish that he resembled some. These processes, occurring with all degrees of clear awareness or obscurity, form part of the tissue of ordinary social intercourse as well as entering into the enjoyment of fiction.

Professor Hardning makes it clear that the use of the term 'identification' tells us nothing about the rich variety of the possibilities of the reader's attitude to fictional characters. Instead of revealing "the perfectly usual and healthy process of having emphatic insight into other people or representations of them«, it may even suggest that there is something pathological about such processes approximating the psychotic delusion of identity with a great man. All such uncertainty can be avoided if we describe each of the processes accurately by speaking explicitly of empathy, imitation, admiration, or recognition of similarities. An adequate account of a reader's attitude to fictional personae should do justice to the complexity of the reading process by identifying its precise elements, rather than lump them all together as 'identification' with the characters.

The idea of vicarious satisfaction, commonly used with the suggestion that the spectator or reader who gives himself up to absorbed sympathy with some character of a novel or a play experiences vicariously whatever the character undergoes, also cannot bear Harding's critical examination. Examining its literal meanings, he makes it clear that the spectator's desires are not in fact satisfied. So the only implied meaning of this term could be sthat viewing a film or reading a novel approximates to having a wishfulfilment dream ... and that the spectator temporarily gets a delusive satisfaction through what amounts to hallucination while he reads or watches. $\ll^{35}$ Though something like this may happen to a few rather unusual people, it is unbelievable as the usual mechanism of reading a novel or viewing a film in which the spectators normally do not suppose themselves actually to be in some world of their fantasy similar to the condition of the opium smokers in a dream. Taking the metaphor of vicarious satisfaction literally obviously cloes not pay the necessary attention to the extent of pathological disorientation implied by such supposed to the extent of pathological disorientation implied by such supposed psychological process.

Professor Harding's own analysis proceeds from the assumption that the wish-fulfilment represents also wa statement of a pressing need or desire, defining the desire at the same time as it offers hallucinated satisfaction ${ }^{36}$ Expressing interests and affirming desires for which ordinary life provides small scope, fiction and drama may come to have a similar function at least for some spectators and readers. In this sense it is not right to say that plays and novels give substitute satisfaction to the spectators' desires; they rather offer "perfectly real, direct satisfaction, but to a muted and incomplete version of their desires $\aleph^{37}$ like many other verbal actions expressing their attitudes. For some spectators they may have a function similar to

34 Ibid., pp. 141-2.

3. Ibid., p. 142 .

36 Ibid., p. 143 .

37 Ibid., p. 143. 
a safety-valve, in some they may precipitate overt action to satisfy desire, and in others, they may be a sufficient and direct satisfaction of the slight degree of interest and desire which they elicit or release.

Giving expression to such desires and interests, fiction and drama make it possible for spectators to join in their expression and gain importantly in »having joined with the novelist or dramatist in the psychological act of giving them (i. e. such desires) statement in a social setting «. ${ }^{38}$ What is called wish-fulfilment in novels and plays should therefore more correctly be described as wish-formulation or the definition of desires and viewed as an important social act, which, though possible at various levels, involves all of them in the same process of saffirming with the author a set of values Fiction can thus be seen as contributing to the definition of the reader's and spectator's values, stimulating his desires rather than gratifying them by some mechanism of vicarious satisfaction, and its importance in the social moulding of readers becomes understandable. It enables the reader to enter imaginatively into the experience of other people:

Emphatic insight allows the spectator to view ways of life beyond his own range. Contemplating exceptional people, he can achieve an imaginary development of human potentialities that have remained rudimentary in himself or been truncated after brief growth; he can believe that he enters into some part of the experience of the interplanetary explorer... The spectator enters imaginatively, with more or less accuracy and fuilness, into some of the multifarious possibilities of life that he has not himself been able to achieve. One of the bonds between ourselves and others, one of our interests in them, is that they have done things that we have not. A great deal of gossip, newspaper reports, memoirs, fiction and drama, serves to remind us of the human potentialities that for one reason or another we have left to others, but the knowledge of which, in a diversified group with highly developed modes of communication, forms one of our social possessions. ${ }^{39}$

Our satisfaction in entering imaginatively into fictional experience beyond our own range derives also from the fact "that we can see in very diverse ways of life certain broad types of experience that we know in our own«, from the possibility of simply familiar experience to the heightening context of more remarkable ways of life, through which the ordinary possibilities may gain an enhanced significance. However, we must never forget the basic fact that the process of looking on and entering imaginatively into other people's activity, or representation of it, does not enlarge the range of the onlooker's experience, but rather of his quasi-experience and partial understanding. "For it has to be remembered that the subtlest and most intense emphatic insight into the experience of another person is something far different from having the experience oneself. «40

The use of the terms sidentification « and »vicarious satisfaction « additionally cannot describe the process of reading so as to give an adequate account of what happens in it. The reader not only feels simply what he imagines the character to be feeling, but also feels, as the onlooker, for him and responds to the fictional situation as a whole. The onlooker's response to

\footnotetext{
${ }^{38}$ Ibid., p. 144.

39 Ibid., pp. $144-5$.

${ }^{40}$ Ibid., p. 145.
} 
the represented characters and events thus goes beyond identification with any one of the characters; he feels for them as well as with them and, as a rule, knows more about the events than the characters are shown as knowing. Rereading a novel or rewitnessing a play can prove the reader's superiority of knowledge beyond doubt.

The more critical reader also knows that the characters of a novel or a play are not real people »but only personae created by the author for the purpose of communication". He is aware of the fact that he is sin a social communication of a special sort with the author and never forgets that the fictional characters are "only part of a convention by which the author discusses, and proposes an evaluation of, possible human experience ${ }^{41}$

Some elements of the process of reading and their importance for the reader are discussed again in "Considered Experience: The Invitation of the Novel (1967). ${ }^{42}$ In this study Professor Harding approaches the problem of the reluctant reader by outlining the kinds of challenge and threat that the willing reader of fiction can expect and the non-reader sacrifices or escapes.

Proceeding from his belief that the possible continuity between daydreams and fiction should be viewed as wish-formulation or definition in which wishes are stated and their fulfilment contemplated in imagination, he argues that love stories and adventure stories can offer partial expression and partial control of the wilder fantasies stimulated for instance by adolescent sex interests and by adolescent aggressiveness. The contemplated possibilities need not all be pleasant; fear-formulation may be as important as wish-formulation, since it may provide a parallel to the child's own anxiety and then demonstrate that even such imaginary peril can be overcome. Fiction can also give enhanced significance to the reader's own life by analogy with the events of the novel or play, thereby imparting unreal glamour to rather ordinary events, or providing a heightened reinterpretation of everyday events for some young readers. At the stage of adolescence, it can also contribute to the reader's search for identity or role definition, since it may allow the reader sto try on various personalities, each of which selectively emphasizes some feature or potentiality of your developing self «. ${ }^{43}$ Besides empathising with characters, young readers may come to evaluate what they do and suffer, and, at least in some measure, also to accept or reject implicitly the values suggested by the author, by his interests and attitudes.

The reader's interest in fiction seems to be related to his interest in other people, his wish to follow their doings, to try to understand their motives and to join with someone else in making an emotional response to their supposed behaviour and experience. Whereas the well-adjusted readers feeling no particular interest in fiction are likely to become interested in it when they come across something puzzling or disturbing in the social life around them, the person with rudimentary social interest is not likely ever to find much appeal in fiction..$^{44}$

4I Ibid., p. 147.

42 "Considered Experience: The Invitation of the Novel." English in Education, Vol. 1, No. 2 (Summer 1967): 7-15.

${ }_{43}$ Ibid., p. 9.

${ }^{44}$ Cf. ibid., p. 15. 
"The Notion of 'Escape' in Fiction and Entertainment" (1967)45 examines the possible meanings which the terms »escape " and "escapist « may yield when applied to the reading of literature and to the pursuit of entertainment. By a careful analysis of the various psychological processes involved in resorting to escape, or rather activities offering escape from some other activity, and by a detailed examination of the answers given by the respondents to his questionnaire in the $1930_{s}^{46}$, Professor Harding illuminates the complexity of the meaning of such terms, and in particular the variety of the attitudes taken to what is commonly named escape in fiction and entertainment. In the light of his critical argument it becomes evident that such a derogatory notion of escape as "refuge from actual life" as maintained by Q. D. Leavis in her Fiction and the Reading Public (1932), can serve as a mere label of disparagement without any precise critical meaning. Since people turn to reading and entertainment for various reasons: for their compensatory appeal, either because they can provide temporary forgetfulness of the analgesic or because they offer positive remedial effect, and since under certain conditions and for certain reasons different kinds of literature, including the literature of the highest quality, may fulfil the compensatory and consolatory function, escape may mean several things that should be differentiated rather than lumped together:

Instead of uncovering any one psychological meaning for 'escape' I have reached three psychological processes one or more of which operates in activities that are commonly called escapist. They are, first, the change from one pursuit to another mainly for the compensatory appeal of the latter; second, the welcoming of regressive pursuits - those which fall below the person's own usual standards; and third, the manipulation of affect, pursuing an emotional state instead of starting from interest in a situation and accepting the emotional state to which exploration leads. This analysis implies that the material of entertainment or literature (a particular novel or play, for instance) cannot be labelled 'escapist' regardless of the function it performs for a given person on a given occasion. ${ }^{77}$

In »Reader and Author" $(1963)^{48}$ and $"$ The Bond with the Author" (1971), ${ }^{49}$ Professor Harding takes up another aspect of the reading process, the obligations of the reader proceeding from the fact that, through reading, he is related not only to the text but also to its author. These two studies, in this sense, come to deal with the problems of communication. Starting from the fact that uncertainties of communication arise because the less conscious implications may not be the same for the reader as they were for the author, or for one reader and another, this study attempts an analysis of both: the

${ }^{45}$ "The Notion of 'Escape' in Fiction and Entertainment." The Oxford Review, No. 4 (February 1967): 23-32.

${ }^{46} \mathrm{Cf}$. notes 14 and 15 for bibliographic details.

47 "The Notion of 'Escape' in Fiction and Entertainment«, p. 32.

${ }_{48}$ "Reader and Author in Experience into Words: Essays on Poetry. (1963) London: Chatto and Windus; pp. 163-174. Harding's awareness of this problem can be ascertained as early as 1936. In a comment entitled »Psychology and Criticism: A Comment", Scrutiny, V (1936): 44-47, he emphasizes that we cannot treat a book as being impersonal as a breaking wave since we inevitably think of it as a human product, as implicitly sanctioning and developing interests and ideals and attitudes of our own.

${ }_{49}$ "The Bond with the Author.« The Use of English, Vol. 22, No. 4 (Summer 1971): $307-19,325$. 
reader's part in reading and the author's control of his meaning. The questions concerning the meaning of literary works are thus in the focus of his attention, ranging from the possibility of the reader's entirely idiosyncratic meanings to the historical changes of meaning resulting in time-added meaning.

Profesor Harding points out that there is nothing wrong with completely idiosyncratic interpretations of poems, art or anything. However, this is not all we want: if we only wanted this, there would be no need for authors and artists. We could simply take a benzedrine tablet and let our imagination loose. If we want to take literature seriously as literature, not just as an object stimulating idiosyncratic responses, we should make an attempt at understanding it in terms in which it has been offered. Though merely private idiosyncratic interpretation of literary works is stimulated by much current criticism, he believes that such interpretation means the loss of the implicit social link between the reader and the author. In a way it affects the work for the reader:

If what he enjoys in a work of art is unconnected with the artist's satisfaction, the work becomes an unintended feature of the world, non-social, like a sunset or a canyon, beautiful perhaps but not mediating contact with the human maker.

Emphasis is laid especially on the social aspect of our enjoyment of literature or of any pleasing object and on the fact that we crave the sense of shared interest and sympathy. The background of a social culture swhich we feel to be supporting or challenging or failing to understand our enjoyment« continues to be in force also when we are by ourselves. In this, Professor Harding reminds us, »we are inescapably social. ${ }^{51}$

In the presence of man-made objects we are not only related to our fellow-onlookers but we also enter in a social relationship with the maker, even if he is unknown or dead. Misunderstandings and mistakes are common in such a relationship, as in other relationships, so that the reader's misconceiving what the author has written cannot be regarded as peculiar at all, yet the reader is not satisfied with such misconceptions:

We are not, however, content to misunderstand; it comes as a disappointment to find that something we valued in an author is based on our misreading. The fact that someone chose to make the work of art in the form we find satisfying, chose at least to the extent of letting it go as finished or publishable, is a vital element of our pleasure in it.

Such considerations lead also to the problems of the author's control of the reader's response. The possibility of less defined and less controlled meanings and associations of words may result in greater uncertainty and idiosyncratic readings with every reader enjoying a different poem. And Professor Harding calls our attention to the difficulty arising from the fact that the author can only offer the verbal component of a pattern of inner experience, the totality of which includes much else besides words and articulate thought.

${ }^{50}$ Experience into Words, p. 164.

51 Ibid., p. 164.

${ }_{52}$ Ibid., p. 165. 
Still he insists on the importance of the bond between the reader and the author, for "a literature is not just a sequence of authors but a growing social structure of which readers form an integral part." "Understanding in the reader and intelligibility in the author are essential to a literature and involve obligations in both. ${ }^{53}$

»The Bond with the Author explores further consequences of this »bond for the reader's private commerce with literature, and its relevance for literature as a social institution. The fact that along with the action and experience of characters the author always presents also his own evaluation of what is done and felt (as heroic, pathetic, contemptible, charming, funny and so on) and implicitly invites the reader to share his attitude, makes it obligatory for the reader to perceive and evaluate these elements also, so the reader's task is not complete unless he tacitly evaluates the author's evaluations and takes his own attitude towards them. The readers may only seldom speak and think about such attitudes, yet their implicit decisions with respect to them form an integral part of their literary experience.

The fact that we practically always experience a work not just as a happening but as "somebody's offering":

Implicitly we think of a work as being offered to us by someone, as having had significance for another person and not being an impersonal accident like the flickering of flames. Part of our own satisfaction is the sense that some other human being found it satisfying to contemplate such and such possibilities of experience and evaluate them in such and such a way, that when we share his satisfaction some mutual sanctioning of values is occurring, and that we have this quasisocial relation with him even if he is dead or totally inaccessible. ${ }^{54}$

has several consequences for its reading. It explains why some readers feel disturbed when an author revises his work in a way they think spoils it, and why abridged books are unsatisfactory. The consequences of this fact are even more far-reaching for editors who, because of this very fact, must not give way to their own preferences. Also the question of the relevance of the biographical knowledge about the author for our reading of his work is related to the same fact: though in principle such knowledge is not necessary or relevant, the reader inevitably wants to fit his work or works and the biographical facts into some sort of a pattern.

If literature is to create the necessary link between the reader and the author, Professor Harding maintains, the author's control of the reader's response must count for something: some degree of control and direction by the author is essential. Though objective demonstrations of misreadings are very hard and sometimes impossible, and our readings are fragmentary and difficult to formulate, we still must attempt to formulate the sense of a work, otherwise we have no way of knowing whether we and other readers are sharing and valuing the same poem for anything like the same reasons. Regardless of its limitations such a formulation of sense is preliminary to

s3 Ibid., p. 173. The problems of the author's intelligibility, or rather ability to control his readers, and the corollary question of the reader's capacity for response are never lost sight of in Professor Harding's criticism. See his discussion of the restricted capacity of Blake's reading public in Experience into Words, pp. 49 and 52 , of Coleridge's leaving his poem as it stands, ibid., p. 71 , and of the problems and origins of obscurity in T. S. Eliot's poetry, ibid., pp. 104 and following.

${ }_{54}$ "The Bond with the Author«, p. 311. 
any discussion of literature and thus necessary to maintain "a living literature characterized by Professor Harding as sa social institution, with an active social or quasi-social process going on between readers and author and between one reader and another .55 This very process contributes to the gradual extension in the relevance of individual works of literature. In this way, sin a process of reinterpreting the literature of the past, of rediscovering some and neglecting very much, of sometimes finding new insights or just establishing a new fashion«, lasting works can be given current relevance by their later readers and kept alive for them.

\section{PRACTICE IN ENJOYMENT OF ARTS}

Along with his endeavour to penetrate into the psychological processes involved in entertainment and reading, to procure a more tenable explanation of what actually happens in them and, on this basis, to provide a more adequate terminology for their description and discussion, Professor Harding has always been interested also in the possibilities of improving these activities. This interest can be traced back to his first study of entertainment in which he writes: 》If its finer possibilities are to be realized, entertainment must be developed for its own sake, with an understanding of its own special function .... ${ }^{56}$

His first attempt to answer the question of how to reach a more qualified enjoyment of arts was given for the field of music in $»$ The Social Background of Taste in Music «57 already in 1938, and conceived in terms of acquiring a genuine taste in music. The first, preliminary answer of psychology seems to be the notion of practice: the enjoyment of a piece of music, in anything like its full complexity, has to be regarded as a skill which the listener must practice to acquire. The amount of practice needed depends on the quality of music and sthe degree of skill and the range of skills in listening which the listener possesses«. Above all, practice cannot and should not be replaced by any other thing:

Practice must not be confused with the intellectual dissection of music, or anything that can be achieved by merely acquiring knowledge about it. It is a matter rather of entering into the music in all its aspects as fully and honestly as one can at each hearing - a matter essentially of attentive enjoyment, attentive dislike, or even attentive bafflement. It means trying to miss as little as possible to pass by without affecting one's total state of mind. Practice of this kind may be of every degree of intensiveness, from merely hearing the same thing over and over again, to the highest degree of concentrated listening. ${ }^{58}$

Irrespective of its great importance, mere practice is not sufficient for the development of good taste, because it tends to remain in one path of

${ }^{55}$ Ibid., p. 317.

56 "Adult Education and Adult Entertainment«, 19. Cf. note 1 for bibliographic details.

${ }_{57}$ »The Social Background of Taste in Music.« The Musical Times, Vol. 79, No. 1143 (May 1938): 333-35 and "The Social Background of Taste in Music II - Individual Growth in Taste." The Musical Times, Vol. 79, No. 1144 (June 1938): 417-19.

${ }_{58}^{5}$ Ibid., p. 417. 
listening only and does not equip the listener for the skilled experience of other kinds of music. The widening of this sphere of skilled enjoyment of music can be aided by criticism and education which have sthe equally necessary task of stimulating the listener to further exploration. They have to promote range and variety in his skills of appreciation, to ask constantly whether an increasingly sensitive response in one particular direction is worth achieving or whether exploration along other lines might not be more rewarding. ${ }^{59}$

The psychological processes involved in the development of the capacity to enjoy arts in general, that is, the processes of practice, exploration and integration, are the main concern of "Skills of Enjoyment $(1948) .{ }^{60}$ In describing the psychological processes which may increase individual responsiveness to works of art Professor Harding uses concrete examples from music, representational arts such as novel and play, visual arts, yet his study as a whole implies that the processes discussed apply to the improvement of appreciation of all the arts.

Practice is the first and most important of these processes. The term is used in a wide sense $»$ to refer to the fact that in certain kinds of activity repeated attentive performance leads to a demand for a more complex form of the same kind of activity. ${ }^{61}$ Especially some intrinsically satisfying lines of human activity seem to invite endless extension and development in which we want not a mere repetition of the last experience but something more complex or extensive or refined, in short, the same kind of activity in a form which we would have found a little too difficult on the first occasion. Skilled enjoyment cannot be mastered without such a repetition resulting in extension and development of taste. Skills of enjoyment are thus always acquired gradually and by practice. It is only because we may acquire them by imperceptible stages that we are not aware of this process. This fact, however, does not diminish the high importance of practice:

The idea of practice in enjoyment is simply that repeated response to the same work of art, if it really is attentive response, creates increasing ability to respond. If the work of art gives no scope for this increased ability we experience some kind and degree of boredom not apathy, but the satiety which can become a desire for further development. ${ }^{62}$

Like many kinds of human activity which are characterized by their capacity for indefinite extension, the idea of practice in gaining skilled response must be freed from any implication of approach to some definite goal. Though it cannot be judged by an objective criterion, practiced response to the arts simply tends to increase the skills of appreciation. The notion of practice also implies specificity: practice in a particular skill of appreciation does not lead directly to the appreciation of other arts; therefore Professor Harding warns us that "there is no unitary ability to enjoy 'the arts' in general but only skills of enjoyment in particular arts or subdivision of them «.63

${ }^{59}$ Ibid., p. 418.

${ }^{60}$ "Skills of Enjoyment.« The Changing World, No. 4 (May, June, July 1948): 16-29. Based on a paper read before the Cambridge New Contemporary Society in February 1947.

61 Ibid., p. 16.

${ }_{2}$ Ibid., p. 19.

${ }^{6}$ Ibid., p. 20. 
He again calls attention to the fact that information about arts must not be mistaken for practice in appreciation:

The attentive practice in the arts which brings an increased ability to respond must not, of course, be confused with accepting instruction or acquiring information or intellectually dissecting what one enjoys. It consists in repeatedly exposing oneself to the work of art as fully as possible, in the hope that on successive occasions less and less of the work will fail to have an effect, and successively fewer features or aspects will escape integration within what we experience as the total effect..$^{4}$

Though practice along a particular line of interest will not lead directly to a different line of interest, long-continued and oft-repeated practice may produce some degree of boredom and induce the person to the exploration of different possibilities, leading him to new and unknown areas of art, to the exercise of new abilities, and to the development of responsiveness to new features or aspects of our surroundings and experience. Offering new insights into the already familiar and making them more vivid, such new possibilities of experience and appreciation may also change the structure of our sentiments and values. In this way the process of exploration of new possibilities comes to invite also the third process of trying to achieve integration and coherence of multiple interests, beliefs, sentiments and attitudes making up our personality. This last process is seen as an effort towards consistency and coherence in evaluations.

It is in the sphere of the last two processes - exploration of new possibilities and their integration - that criticism can be of use, since sit stimulates exploration, and it draws attention to the implications of particular value judgements and points of relevance and relationships that might be overlooked. ${ }^{65}$ In accordance with this concept of criticism, Professor Harding feels that criticism should not try to do more than offer opportunities for revising value judgements, even though as social beings we all desire the satisfaction of having the sympathy and sanction of other people for our interests and appraisals, and may also resort to different means of persuasion to obtain such a sanction.

The concept of criticism as anticipated in "The Social Background of Taste in Music « and »Skills of Enjoyment« is strictly adhered to and developed for literary criticism in "The Literary Critic " (1953). ${ }^{66}$ Professor Harding emphasizes that criticism ought not to spare the people the trouble of reading books worth reading, but should rather stimulate fully personal response to them and encourage the reader to return to them with an unsettled mind and new questions. The first test of the critic's usefulness to the reader is whether the critic gives the reader the opportunity and incentive to read more effectively for himself. With modern and unfamiliar literature, the critic need not make our reading easy; he should rather help us surpass the simple hostility and derision that spring from having our preconceptions and expectations disappointed. In such conditions the critic's job is sto prepare us for the unexpected features of a new work. He may - he should - go on to question whether they justify themselves, but he

\footnotetext{
${ }^{64}$ Ibic., pp. $20-21$.

is Ibid., p. 28.

${ }_{66}$ "The Literary Critic." The Listener, October 15, 1953, pp. 637-38.
} 
must first make the effort of grasping, and helping us to grasp, what it is that the author has really aimed at. ${ }^{67}$

Also in the sphere of evaluation the critic should not spare his readers the responsibility of making their own appraisal:

$\mathrm{He}$ will not, if he is wise, pretend to be the mouthpiece of fixed and unquestionable critical canons. What he has to report are his personal experiences in the presence of the work of art and the judgement he suggests must remain simply a suggestion, to be confirmed or modified by other readers on their own responsibility. ${ }^{68}$

The readers should exercise their own capacity to respond and take their own responsibility in value judgements; they should agree intelligently or disagree precisely and profitably on the basis of the critic's description of the features and aspects of the work leading him to his evaluation.

"Practice at Liking: A Study in Experimental Aesthetics ${ }^{69}$ describes and presents the results of an experimental investigation of the changes in the reader's likes and dislikes for poetry. It proceeds from the assumption that the effect of social pressure - persuasion, suggestion and received opinion - on the reader's assessment of a work of literature is so striking that other processes affecting liking and preference for poetry receive less attention and are accordingly less known. That is why Professor Harding has decided to study the process of familiarization of a poem as a relatively non-social factor in the reader response. The aim of his study was »to examine the possibility that increasing familiarity with poems, in the absence of social influences such as instruction, persuasion or discussion, would produce systematic changes of evaluation; and, further, that the nature of the changes would be in part predictable on the assumption that repeated readings of a poem can be viewed as practice at a task. ${ }^{70}$

Thirty poems or self-contained passages from longer poems were given, without the author's name, to 139 readers. The subjects attended the laboratory twice, at an interval of a week, and read and assessed the 26 poems twice on each occasion. The subjects were first- or second-year female undergraduates studying science and arts. They volunteered for experimental work »on a psychological problem connected with reading«. The poems were of varied style and difficulty. The subjects were requested to express their appraisal solely in terms of their present liking and their expectation of what satisfaction further reading might yield. On each of the four trials they were requested to put the poems in one of the following categories:
A: too difficult but perhaps promising;
$\mathrm{B}$ : attractive and understood, and perhaps capable of yielding more;
C: attractive but easy, and not likely to yield more;
$\mathrm{D}$ : unappealing and unlikely to increase in appeal. ${ }^{71}$

The results were calculated on 26 poems and represented statistically. They show that the changes in assessment take a consistent trend attributable

67 Ibid., p. 637.

68 Ibid., p. 638 .

${ }^{69}$ "Practice at Liking: A Study in Experimental Aesthetics." (Fourth C. S. Meyers Lecture delivered on $15^{\text {th }}$ November 1967.) Bulletin of the British Psychological Society, Vol. 21, No. 70 (January 1968): 3-10.

${ }_{70}$ Ibid., p. 3.

71 Ibid., p. 4. 
to the cumulative effect of practice, rather than the form of oscillations which would occur in the absence of systematic effects. The results thus confirmed the broad expectations in most respects. The process of familiarization first increases the subject's command of the complex skills of understanding and evaluating the poems. Between the last two trials, however, as their skill has increased, the subjects settle down to a less changeable way of responding, though their responses do not coincide with the responses of other subjects. Thus the results of this study seem to lead to the conclusion that the element of practice is brought to the fore when the reader is left on his own with the task of reading poems, without persuasion, simply given the chance to acquire what skill he can in his own way. The successive classifications of individual readers can be seen as stages in the acquisition of some degree of skill.

$$
* * * *
$$

The foregoing presentation of Professor Harding's work shows that his investigations of man-related problems of entertainment, art, the reading process and of their impact upon man and society proceed from his broad cultural interest which enables him to see these activities in their wider social context. Even though his fastidious choice of language and his argument reveal the sensibility of the finest literary critic and his English scholarship transpires through the wealth of well-chosen literary examples, the point of departure of his studies must be regarded as primarily psychological. This approach seems to carry into practice his belief »that psychology ought to be of importance to things outside itself $\ll^{72}$ and his hope sthat a scientific discipline could clear the ground in such a case and make some small advances toward greater probability in judging the validity of seemingly subtle or profound insights into complex topics $\ll$ which, as he says, brought him to psychology. ${ }^{73}$ His twofold specialization in English studies and in psychology has thus resulted in an interdisciplinary approach which seems to be particularly appropriate for his studies.

The psychological point of departure determines his concept of entertainment and the reading process, his manner of examining and describing these two activities, and also his evaluation of their significance for individuals and for society as a whole. Entertainment and the reading process are thus conceived as normal human activities which do not constitute a separate category, but are rather continuous with and significantly similar to other human activities, and are accordingly to be examined as such in their basic relatedness to other pursuits. Consequently, Professor Harding embarks on the examination of the psychological processes that can be distinguished in reading and never conceives of it in such metaphorical terms as some of contemporary critics, as for instance the transplantation of experience from one mind to another, ${ }^{74}$ or in terms of some more modern trends such as the process of assembling the text's meaning, or as

${ }^{72}$ Ibid., p. 3.

${ }^{73}$ "Psychological Problems in the Recognition of Excellence." (Address) The Advancement of Science, Vol. 10, No. 38 (September 1953), p. 22.

${ }^{74}$ Lascelles Abercrombie, Principles of Literary Criticism. London: Victor Gollancz, 1932, p. 24. 
san activity guided by the text; this must be processed by the reader, who is then, in turn, affected by what he has processed $\ll{ }^{75}$

His analysis, of entertainment and the reading process proceeds from the description of the social situation set up by these two activities in which the entertainer or the speaker "presents what he takes to be an interesting situation - actual or possible - in what he regards as an appropriate light it in such a way makes it clear that whe expects audience to agree that the situation is interesting and the attitude taken up towards it appropriate; implicitly he is asking for their sanction for his interests and evaluations « ${ }^{76}$ The perception of this situation in its wider social context makes it possible for Professor Harding to explain what occurs in it: a reciprocal sanctioning of the interests, ideals, and attitudes between the public and the speaker resulting in an influence upon the emotional life and values of people.

The differentiation of the various attitudes on the part of the speaker or writer: his selection of an interesting experience to portray, his taking a supposedly fitting attitude to it and suggesting or expecting that the reader take the same attitude or approve of the attitude taken, calls to mind I. A. Richards' famous presentation of the four different functions of language. The four different kinds of meaning related to the several tasks which language has to perform simultaneously are listed in Practical Criticism (1929) as: 1. sense, directing the hearer's attention upon some state of affairs, 2. the simultaneous expression of the speaker's feeling about such items, 3. the tone expressing the speaker's attitude to his listener, and 4. the intention conveying his purpose. ${ }^{77}$ The similarity between the two differentiations of the speaker's attitude, however, leads to no similar conclusion: whereas I. A. Richards sees an additional source of misunderstanding in the possibility of the reader's garbling the sense, mistaking the tone and disregarding the intention, Harding sticks to the social nature of the situation. The writer and the reader take part in it as social beings interested in the experience of fellow human beings and desirous of their social sanction of their own interests, attitudes and values, the writer offering what he has to say and the reader approving or disapproving of what is said and the manner in which it is offered in accordance with his own views and values. This situation is thus seen as placing the reader and the author in a special social relationship, and on this basis Professor Harding construes his concept of the reader's bond with the author, which obliges the reader to try to understand the meaning of a literary work as an offering by the author and not to let his imagination loose to produce idiosyncratic meanings. The range of acceptable meanings is for Harding defined by this essential bond, the social relationship to be established between the reader and the author, and determined by the latter's satisfaction in his work regardless of his original intention. ${ }^{78}$

${ }^{75}$ Wolfgang Iser, The Act of Reading. London: Routledge \& Kegan Paul, 1978, p. 163.

${ }_{76}$ See notes 24 and 2.

${ }^{77}$ I. A. Richards, Practical Criticism. New York: Harcourt, Brace \& Co., 1929, pp. $174-6$.

${ }_{78}$ Experience into Words, p. 166: "What he (the author) intended to write at any moment prior to the arrival of words is not of crucial importance; the question is what he accepted as part of his poem." 
Professor Harding's concept of the basic situation of entertainment and reading, its similarity to gossip, and of the social bond between the reader and the author, seems to come closer to the later speech-act theories of literature which it anticipates. If we take as an example Mary Louise Pratt's work Toward a Speech Act Theory of Literary Discourse (1977) ${ }^{79}$ some similarities are easily visible - despite her use of different linguistic terminology - in the heavy emphasis she lays on formal and functional resemblance between the literary and natural narratives. She also points out that oral narrative of personal experience is a speech act exceedingly familiar to everybody, because verbal rendering and display of experience constitute a fundamentally human activity. Though her work shows no evidence of her knowledge of Harding's writings, her descriptions of the basic narrative situation inevitably remind us of his analyses:

In making an assertion whose relevance is tellability, a speaker is not only reporting but also verbally displaying a state of affairs, inviting his addressee(s) to join him in contemplating it, evaluating it, and responding to it. His point is to produce in his hearers not only belief but also an imaginative and affective involvement in the state of affairs he is representing and an evaluative stance toward it. He intends them to share his wonder, amusement, terror, or admiration of the event. ${ }^{80}$

And like Professor Harding she directly proceeds to indicate that literary works share this narrative situation with the natural narrative:

However, we ultimately wish to characterize this verbal experiencedisplaying, experience-sharing activity (I have not begun to do so adequately), it is clear that literary works, or at least a great many of them, are also examples of it. Like the natural narrator, the speaker of a literary work is understood to be displaying an experience or a state of affairs, creating a verbal version in which he, and we along with him, contemplate, explore, interpret, and evaluate, seeking pleasure and interpretive consensus. ${ }^{81}$

Along with the obvious similarities between both descriptions of the narrative situation, even a provisional comparison of both concepts reveals also important differences. Pratt proceeds primarily from a linguistic point of view, so her interest is centred on the questions of meaning, especially the limitations imposed by the speech act concept of literature on various textual and structuralist "free interpretations, whereas Professor Harding undertakes, as we have seen, the task of analyzing also the wider social consequences of this situation.

The attempt to offer a profounder examination and a more accurate description of entertainment and of the reading process by the use of psychology accounts for Professor Harding's primary concern with identifying what actually happens in these two activities in different concrete situations and under various circumstances. Following his own recommendation of what is necessary to understand an activity, ${ }^{82}$ his painstaking, minute

${ }^{79}$ Mary Louise Pratt, Toward a Speech Act Theory of Literary Discourse. Bloomington: Indiana University Press, 1977.

${ }^{30}$ Ibid., p. 136.

"Ibid., p. 140.

${ }^{82}$ Cf. note 20. 
description of every element and detail of entertainment and reading avoids a priori assumptions and generalizations devoid of understandable meaning. It moves from one element to another and sometimes takes up for further examination a single concept or previously neglected aspect years after he first scrutinized it. His analyses naturally proceed from the examination of the contemporaneous state of knowledge about the problem discussed and are often motivated also by his critical dissatisfaction with this state. Thus he is concerned with the fact that entertainment never receives the sort of serious consideration that is given to other human activities and is not discussed in relation to the rest of human lives, in terms of its purpose and function. He is critical of the manner and vague terminology whereby the reading process is spoken about in terms of $»$ some rather vague waffle compounded of psychoanalysis, sociology and literary criticism «, ${ }^{83}$ which would be unacceptable in the description of how a rat learns a maze. Professor Harding's criticism is thus directed against much contemporaneous discussion of the reading and some concepts used in it: "a good deal of pseudo-psychologizing that sees the process of novel-reading as one of identification and vicarious satisfaction ${ }^{84}$ It sets out to refute Jung's prevailing view that $\gg$ The cinema... like the detective story, makes it possible to experience rvithout danger all the excitement, passion and desirousness which must be repressed in the humanitarian ordering of life,$^{85}$ and to criticize Q. D. Leavis's notion that much novel-reading is the indulgence in wish-fulfilment fantasies, as expressed in her Fiction and the Reading Public (1932). ${ }^{86}$ The need and the importance of Harding's polemic against such theories and concepts - in particular of his insistence on the unreality of any such psychological processes as vicarious satisfaction or an undefined identification of the reader in the process of reading become evident only in the light of the fact that such concepts continue to be used by prominent scholars in spite of his illuminating analysis of their inadequacy and possible pathological suggestions. ${ }^{87}$

His critical analysis of the reading process reveals the need for the recognition and examination of some other activities which constitute an integral part of it. Besides perception and comprehension which are preliminary, he underlines the importance of the reader's imaginative or emphatic insight into other living things and of his evaluation of the characters and what they undergo in the relation to his own value scheme, along with the evaluation of the fittingness of the author's attitude to what is presented.

${ }^{83}$ „Psychological Processes in the Reading of Fiction«, p. 133. Cf. note 26 for bibliographic details.

${ }_{84}$ Ibid., p. 140.

${ }^{85}$ Ibid., p. 142. See also Harding's review C. G. Jung's Modern Man in Search of a Soul in Scrutiny, III (1934), p. 110 saying "But he (Jung) is so vague and unscientific - his tone is something between the conversational and oracular - that he adds little to what we have probably felt for ourselves."

${ }^{B}$ Q. D. Leavis, Fiction and the Reading Public. London: Chatto and Windus, 1932. Harding refers in particular to the chapter "Living at the Novelist's Expense .

${ }_{87}$ Suffice it to list only two outstanding studies:

Norman N. Holland, The Dynamics of Literary Response. New York: Oxford University Press, 1968. Chapter 10, "Character and Identification", pp. 262-280.

Hans Robert Jauss, Asthetische Erfahrung und literarische Hermeneutik. Frankfurt: Suhrkamp, 1984. 
Both these activities claim reader's active participation and support Harding's view that the concept of reader's passivity is out of keeping with what actually happens in reading. His emphasis on the imaginative elements in the reading process is based on a meticulous examination of human capacity to imagine possible human experience in various circumstances, and on the scrutiny of the multiple reasons for such imaginative activity. Drawing on every possible examination of such activities reaching back to the earliest childhood, the most recent trends in the study of the role of fictions in human lives seem, decades later, to prove Professor Harding's emphasis on imaginative activities to be well-founded. Richard Kuhns, one of the several authors who convened to discuss the integrative function of fictional objects, notably art, writes:

The inherited creations, the "made" events, are probably more important in the process of giving a structure to consciousness than any other kind of event, including natural events. ${ }^{88}$

In this description he comes close to Harding's concept of the effects of reading and entertainment.

It must be pointed out that Harding's original approach to and insights into the reading do not result only from his painstaking and conscientious examination of the reading process and its elements which avoids any entanglement with evaluations and shows his everpresent awareness that much is still unknown in this complex area of human activities. They can be understood only against the background of his wide psychological knowledge, above all in his special field of social psychology, which is not limited to western cultures only but can use a variety of other cultures for comparison.

When Professor Harding turned to examine entertainment and the reading process he was obviously confronted with the same situation, or rather state of affairs, as many other British authors concerned with the effects of the so-called mass culture of the $20 \mathrm{~s}$ and $30 \mathrm{~s}$ in England, like F. R. Leavis, Q. D. Leavis, the Lynds and many others. ${ }^{89}$ With all of them he shared a common concern with the then undesirable »debased " state of (mass) culture. Out of this common concern there grew various explanations and different recommendations for solutions. As we have seen, Professor Harding clearly voiced his dissatisfaction with the contemporaneous treatments of entertainment and the persisting descriptions of reading. Thus he explicitly rejected the opinion that entertainment should

ss Richard Kuhns, "The Cultural Function of Fiction" in Funktionen des Fiktiven, ed. by Dietrich Heinrich and Wolfgang Iser. München: Wilhelm Fink, 1983 , p. 62.

${ }_{89}$ Cf. F. R. Leavis, Mass Civilisation and Minority Culture. Cambridge: Minority Press, 1930. F. R. Leavis and Denys Thompson, Culture and Environment. London: Chatto \& Windus, 1933. See also Professor Harding's reviews: "The Conception of Leisure." Review of Leisure: A Suburban Study, by George A. Lundberg; of The Bleak Age, by J. L. Hammond and Barbara Hammond; and of The Machine and the Worker, by A. Barratt Brown. The Sociological Review, Vol. 27, No. 3 (July 1935): 359-62. "Vitality in Social Surveys." Review of Middletown in Transition, by Robert S. Lynd and Helen Herrell Lynd, and of May the Twelfth, Mass-Observation Day-Survey, ed. by Humphrey Jennings et al. Scrutiny, VI (1937): 313-15. 
be replaced by something less objectionable and set out to examine several misconceived notions of the spectator's and reader's passivity, escapist attitudes, naive identification and vicarious experience. His explicit reason for the rejection of such views is that they offer no basis for further examination of these activities which would make possible their improvement.

Professor Harding's alternative seems quite clear: since it is quite obvious that entertainment, notwithstanding all of its argued qualities, must have appeared to satisfy some existent needs it should be studied and then improved to be sas good as it might be«. In this his attitude to entertainment differs from the attitude of other critics. He never merely criticizes the existent conditions like some other critics of the time, but rather insists on the necessity to examine them and even sets out to determine them by means of a questionnaire addressed to the readers of The Highway. So for instance he does not deplore the low taste in music but rather considers it «a failure to educate an unprecedented mass of listeners «. ${ }^{0}$ Similarly he never criticizes or even reproaches less practiced readers for their inability to derive satisfaction from more serious literature. On the contrary, he claims that trashy literature may have high intrinsic appeal for people of less practiced taste, and for them may not be escapist at all. ${ }^{91}$ Every human being - in his opinion - has the right to satisfy his needs in accordance with his capacities.

And yet each of us is the equal of all others in this sense: that he has an equal right to live his own life, and that everyone's supreme satisfaction lies in fulfilling himself and developing whatever capacities he may have. I have no right to say even to a mental defective "Your life counts for less than mine ${ }^{92}$

In accordance with this he never accepts or uses Q. D. Leavis's division of the readers into high-, middle-, and low-brow readers, or any other derogatory description of readers or consumers of popular entertainment, but rather strictly speaks of less practiced and more practiced readers and tastes.

This need for tolerance is strictly observed in his concept of the function of literary criticism, which can be said to go a step beyond T. S. Eliot's famous statement: "The critic must not coerce, and he must not make judgments of worse or better. He must simply elucidate: the reader will form the correct judgment for himself. ${ }^{93}$ in explaining why the reader must be induced to take his own value decisions in accordance with his own value system and accept responsibility for such decisions. He not only sees nothing disturbing if - in the absence of any cogent external authority to appeal to - people differ in their critical opinions, ${ }^{94}$ but believes

90 "The Social Background of Taste in Music«, p. 333. For bibliographic details see note 68 .

${ }^{91}$ "The Notion of 'Escape' in Fiction and Entertainment«, p. 23. Cf. note 45 for bibliographic details.

${ }_{92}$ "Social Background of Nursing - Part 1.« Nursing Mirror, October 30, 1948, p. 70.

${ }_{93}$ T. S. Eliot, The Sacred Wood. London: University Paperbacks, 1960, p. 11. The essay "The Perfect Critic« was originally published in 1928.

${ }^{94}$ "Skills of Enjoyment«, p. 29. Cf. note 71 for bibliographic details. 
any effort at standardization unnecessary and undesirable: „We should still be unwise to impose it by means of psychological and administrative machinery on people who judged differently. ${ }^{95} \mathrm{He}$ disbelieves in the possibility of any "purely individual judgment " without social influences ${ }^{96}$ and clearly asserts: "All our judgements are made in social context and this affects them as inevitably as our perception of an object is affected by its physical background. «97 Such views, however, do not lead him to neglect the possibility of higher standards of the arts; on the contrary, he is constantly interested in the possibilities of improvement on the basis of profounder studies, and especially by means of practice as a possibility of acquiring a more skilled response to the arts.

His notion of practice by means of which greater skill in the enjoyment of the arts can be acquired proceeds from his basic assumption that an adequate experience of art, especially largely unknown modern art, is a complex activity demanding previous practice. This view also makes it necessary for him to conceive the individual's present skill as changeable: determinable for a given person at a given time, but subject to change, notably to improvement by practice. Such a concept seems to imply also a concept of an integrated personality capable of developing his multiple possibilities and accordingly also of improving his capacity to experience art at a more skilled level. Harding's studies are too down-to-earth to ever attempt even a preliminary outline of any such ideal. Regardless of harsh realities such a concept seems necessary at least as an ideal to sustain the belief in the possibility of improvement. Close scrutiny of his writings perhaps permits detection of some elements of such a concept. Trying to outline the new role of industrial psychology in 1933, he writes that the worker should not be regarded as a working mechanism but primarily as a living being whose work can only be understood as an integral part of his life. ${ }^{98}$ Only a year later, speaking about how adult education neglects the capacity for feeling and evaluating, he asks provocatively: "Of what use are information and the ability to think clearly in certain directions if they leave their possessor at the mercy of every charlatan of feeling who produces a film or writes a popular song? « and adds that a person educated in this limited way is surely pathetic. ${ }^{99}$ In his comment concerning the values of an industrial society in 1956, he again calls attention to the limitations of such a scale of values and any education preparing people for service to industry: $\gg$ Education in a proper sense would be at least as much concerned with the quality of living in the rest of our lives. ${ }^{100}$

${ }_{95}$ "English and Intelligence." The Use of English, Vol. 2, No. 3 (Spring 1951), p. 123.

"Skills of Enjoyment«, p. 29. See note 73.

${ }^{97}$ "The Social Background of Taste in Music«, p. 333. See note 68.

98 „Some Social Implications of Industrial Psychology." The Highway, Vol. 25 (March 1933), p. 22.

92 "Adult Education and Adult Entertainment«, pp. 22-3. Cf. note 1 for bibliographic details.

${ }_{100}$ "Values in an Industrial Society: A Comment." In His Royal Highness the Duke of Edinburgh's Study Conference on the Human Problems of Industrial Communities within the Commonwealth and Empire, 9-27 July 1956. Volume II: Background Papers, Appendices and Index (1957). London: Oxford University Press, p. 6. 
Professor Harding's examination of the psychological processes traceable in entertainment and in reading at the present state of the development of psychology first reveals new insights into these two activities; these insights are of great interest to everybody concerned with literature and entertainment, especially to teachers, critics and those readers who have come to wonder what exactly they are doing when they read. His analyses of what happens to people engaging in entertainment and reading also offer new insights into the impact of these activities upon individuals, and thereby into their wider cultural function. They make it quite clear that entertainment and reading are not only temporary distractions offering an escape from whatever part or aspect of reality the person wants to run away and leaving whoever indulges in them in a state of complete passivity. They are first and foremost the activities which, in offering various possibilities of human experience for consideration in a special social communication and for a complex evaluation, may come to have a deeper effect leading to a permanent formative impact upon their consumer's outlook, expectations of what is likely to happen, emotional attitudes and value system. In this way they may come to exercise a profound influence upon whole communities by sanctioning social values and emotional life. Professor Harding's studies thus furnish a detailed psychological description of the ways in which the process of the social construction of reality takes place, in particular of the role of entertainment and reading in this process. ${ }^{10 i}$ Besides this, his various analyses offer also a sounder basis for a more persuasive argument about the importance of literature and the arts and whatever may be classified as entertainment than any offered by the critics professing the importance of elite or by other apologists for literature. We can see in them also a warning about the possible influence of mass media unthinkable in the time when Professor Harding started to examine the reading process and entertainment $» .$. very many years ago, in the 1930s, when the cinema still flourished and television was unknown. «102

It is hoped that our presentation has revealed at least some features of the striking originality of Professor Harding's work: his choice of the problems to be treated as a whole and in terms of details and aspects, his approach and treatment of them, his independent-minded opinion and challenging argumentation, and his suggestions of possible solutions of improvement and resulting analyses. It is hard or even impossible to speculate whether such originality of his work is to be related primarily to his twofold specialization in psychology and in English studies, which has made available to him profound knowledge of two different spheres that is most profitably combined in his studies of entertainment and the process of reading, or to any other particularity of his interest, accident of his life or feature of his personality. However, it seems quite certain that without such a combination and breadth of knowledge his studies could not have taken the same original development and yielded the same results. Along with his interest in the

${ }^{101}$ Peter L. Berger and Thomas Luckmann, The Social Construction of Reality. A Treatise in the Sociology of Knowledge. New York: Doubleday \& Company, 1967, p. 68. See also the discussion of the importance of conversation, p. 152, for a comparison with Harding's notion of the role of gossip.

${ }^{102}$ "The Notion of 'Escape' in Fiction and Entertainment«, p. 24. See note 45 for bibliographic details. 
unknown and previously undiscussed aspects of entertainment and the reading process, this twofold specialization contributes to make his work different from both purely literary and solely psychological discussion of the same subjects. Perhaps it is the newness of his interdisciplinary approach that must be held responsible for the fact that some of his original results have been slower to assimilate than some other authors' more conventional and less complex opinions. 